\title{
3-Hydroxy-8,14-secogammacera-7,14-dien-21-one: A New Onoceranoid Triterpenes from Lansium domesticum Corr. cv kokossan
}

\author{
Zulfikar ${ }^{1}{ }^{1}$, Nurul Kamila Putri ${ }^{1}$, Sofa Fajriah ${ }^{2}$, Muhammad Yusuf ${ }^{1}{ }^{\circledR}$, Rani Maharani ${ }^{1}$, \\ Jamaludin Al Anshori ${ }^{1}$, Unang Supratman ${ }^{1,3}$ and Tri Mayanti ${ }^{1, *} \mathbb{C}$ \\ 1 Department of Chemistry, Faculty of Mathematics and Natural Sciences, Universitas Padjadjaran, Jatinangor \\ 45363, West Java, Indonesia; zulfikar15002@mail.unpad.ac.id (Z.); kpnurul@gmail.com (N.K.P.); \\ m.yusuf@unpad.ac.id (M.Y.); r.maharani@unpad.ac.id (R.M.); jamaludin.al.anshori@unpad.ac.id (J.A.A.); \\ unang.supratman@unpad.ac.id (U.S.) \\ 2 Research Center for Chemistry, Indonesian Science Institute, Serpong 15314, Banten, Indonesia; \\ sofa002@lipi.go.id \\ 3 Central Laboratory, Universitas Padjadjaran, Jatinangor 45363, West Java, Indonesia \\ * Correspondence: t.mayanti@unpad.ac.id; Tel.: +62-0813-201-02633
}

Received: 24 August 2020; Accepted: 10 September 2020; Published: 30 September 2020

Abstract: A new onoceranoid triterpenes, namely 3-hydroxy-8,14-secogammacera-7,14-dien-21-one (1), has been isolated from the fruit peels of Lansium domesticum Corr. cv kokossan. The structure of 1 was determined on the basis of spectroscopic data including infrared, 1D and 2D-NMR, as well as high resolution mass spectroscopy analysis. Compound $\mathbf{1}$ showed a weak activity against MCF-7 breast cancer cell lines.

Keywords: Lansium domesticum; Meliaceae; MCF-7; triterpene onoceranoid

\section{Introduction}

Lansium domesticum Corr. (Meliaceae) is a popular plant that widely grows in southeastern Asia [1,2]. L. domesticum Corr. cv kokossan (Meliaceae) is a higher tree growing up to $30 \mathrm{~m}$ in height, commonly called "kokosan" in Indonesia [3]. Several bioactive triterpenoids have been isolated from L. domesticum [4-9], of which some have shown potential anticancer [10], antibacterial [11], insecticides [12], antimalarial [13], antimutagenic [14,15], and antifeedant activities [16]. Previously, we isolated six triterpenes from the seeds and bark of L. domesticum Corr. cv kokossan [2,16]. In this paper, we report the isolation and structural elucidation of the new onoceranoid triterpenes 1 (Figure 1), along with its cytotoxic activity against MCF-7 breast cancer lines.

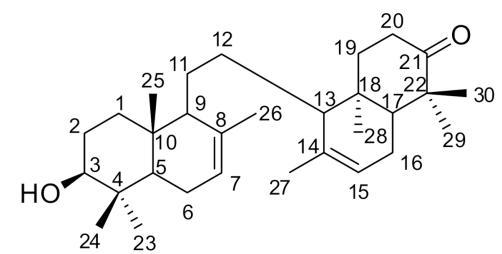

Figure 1. Chemical Structure of compound 1. 


\section{Results}

\section{Extraction and Isolation}

The dried fruit peel $(1.7 \mathrm{~kg})$ was extracted with $n$-hexane, ethyl acetate, and methanol three times, respectively, for $24 \mathrm{~h}$, at room temperature. After solvent removal under reduced pressure, we obtained the $n$-hexane ( $86 \mathrm{~g}$ ), ethyl acetate $(110 \mathrm{~g})$, and methanol (75 g) crude extracts. A portion of $n$-hexane (60 g) was subjected to vacuum liquid chromatography over silica gel using a $10 \%$ gradient of $n$-hexane/EtOAc (10:0-0:10) to afford eight fractions $(\mathrm{A}-\mathrm{H})$. Fraction $\mathrm{D}(6.7 \mathrm{~g})$ was subjected to vacuum liquid chromatography, eluted by a 1\% gradient of $n$-hexane/EtOAc (100:0-85:15) to afford five combined fractions (D1-D5). Fraction D4 was then subjected to silica gel column chromatography, eluted with $n$-hexane:acetone:methanol (7:2.5:0.5), resulting in four fractions (D4A-D4D). Compound 1 was obtained from fraction D4B as a white crystal $(0.27 \mathrm{~g})$.

3-Hydroxy-8,14-secogammacera-7,14-dien-21-one (1), white crystal, m.p. $153-155{ }^{\circ} \mathrm{C},[\alpha]^{20} \mathrm{D}-3.0^{\circ}$ (c $0.1, \mathrm{MeOH}$ ), HR-TOF-MS m/z $463.3569[\mathrm{M}+\mathrm{Na}]^{+}$(calcd. for $\mathrm{C}_{30} \mathrm{H}_{48} \mathrm{O}_{2} \mathrm{Na}, m / z$ 463.3552); IR (KBr) $v_{\max }\left(\mathrm{cm}^{-1}\right): 3533,2932,1700,1456 ;{ }^{1} \mathrm{H}-\mathrm{NMR}$ and ${ }^{13} \mathrm{C}-\mathrm{NMR}$ showed in the Table 1 . Compound $\mathbf{1}$ was evaluated for its cytotoxic acitivity against MCF-7 breast cancer cell line, and compared to doxorubicin $(35.7 \mu \mathrm{M})$ as a positive control. Compound $\mathbf{1}$ exhibited weak activity against MCF-7 with an $\mathrm{IC}_{50}$ value of $717.5 \mu \mathrm{M}$.

Table 1. ${ }^{13} \mathrm{C}$ and ${ }^{1} \mathrm{H}$ NMR Spectral Data of Compounds 1 in $\mathrm{CDCl}_{3}$.

\begin{tabular}{|c|c|c|}
\hline Position & $\delta_{\mathrm{C}} \mathrm{ppm}$ & $\begin{array}{c}\delta_{\mathrm{H}} \text { ppm } \\
(\text { Int, mult., } J=\mathrm{Hz})\end{array}$ \\
\hline 1 & 37.5 & $1.14 ; 1.86(2 \mathrm{H}, m)$ \\
\hline 2 & 27.4 & $1.65(2 \mathrm{H}, m)$ \\
\hline 3 & 79.1 & $3.29(1 \mathrm{H}, d d, 11.3 ; 4.3)$ \\
\hline 4 & 38.7 & - \\
\hline 5 & 51.5 & $1.62(1 \mathrm{H}, m)$ \\
\hline 6 & 29.8 & $1.35 ; 1.50(2 \mathrm{H}, m)$ \\
\hline 7 & 121.7 & $5.40(1 \mathrm{H}, b r s)$ \\
\hline 8 & 135.4 & - \\
\hline 9 & 55.3 & $1.66(1 \mathrm{H}, m)$ \\
\hline 10 & 36.5 & - \\
\hline 11 & 24.1 & $1.99 ; 2.10(2 \mathrm{H}, m)$ \\
\hline 12 & 23.5 & $1.98 ; 2.10(2 \mathrm{H}, m)$ \\
\hline 13 & 56.0 & $1.59(1 \mathrm{H}, m)$ \\
\hline 14 & 134.9 & - \\
\hline 15 & 122.3 & $5.40(1 \mathrm{H}, b r s)$ \\
\hline 16 & 29.9 & $1.35 ; 1.50(2 \mathrm{H}, m)$ \\
\hline 17 & 49.6 & $1.20(1 \mathrm{H}, m)$ \\
\hline 18 & 36.5 & - \\
\hline 19 & 38.4 & $1.51 ; 2.15(2 \mathrm{H}, m)$ \\
\hline 20 & 34.7 & $2.29 ; 2.77(2 \mathrm{H}, m)$ \\
\hline 21 & 217.0 & - \\
\hline 22 & 47.5 & - \\
\hline 23 & 27.9 & $1.00(3 \mathrm{H}, s)$ \\
\hline 24 & 15.1 & $0.87(3 \mathrm{H}, s)$ \\
\hline 25 & 13.3 & $0.99(3 \mathrm{H}, s)$ \\
\hline 26 & 22.3 & $1.75(3 \mathrm{H}, s)$ \\
\hline 27 & 22.4 & $1.72(3 \mathrm{H}, s)$ \\
\hline 28 & 13.6 & $0.76(3 \mathrm{H}, s)$ \\
\hline 29 & 22.1 & $1.12(3 \mathrm{H}, s)$ \\
\hline 30 & 25.0 & $1.08(3 \mathrm{H}, s)$ \\
\hline
\end{tabular}




\section{Discussion}

The molecular composition of 1 was proposed as $\mathrm{C}_{30} \mathrm{H}_{48} \mathrm{O}_{2}$ with seven degrees of unsaturation, based on HR-TOF-MS and NMR spectral data. Mass spectra showed molecular ion peak at $m / z 463.3569$ $[\mathrm{M}+\mathrm{Na}]^{+}$, with calculated $m / z 463.3552$ for $\mathrm{C}_{30} \mathrm{H}_{48} \mathrm{O}_{2} \mathrm{Na}$. The IR spectrum exhibited bands at $v_{\max }$ $\left(\mathrm{cm}^{-1}\right) 3533$ (hydroxy), 2932 (C-H stretching of aliphatic), 1700 (ketone), and 1456 (gem dimethyl).

The ${ }^{13} \mathrm{C}$ NMR data (Table 1) with DEPT and HSQC experiments (Figures S2-S4) revealed the presence of total of 30 carbon signals, which were classified as eight methyls, eight methylenes, seven methines (two olefinic and one oxygenated), and seven quaternary carbons (two olefinic and one carbonyl). The two trisubstituted double bonds and the carbonyl in a system with seven degrees of unsaturation suggested that $\mathbf{1}$ possess a tetracyclic structure. Previous studies supported that evidence, indicating that compound $\mathbf{1}$ has an onoceranoid-type triterpenoid [3,14].

The ${ }^{1} \mathrm{H}$ NMR spectrum of $\mathbf{1}$ (Figure S1) displayed the presence of eight methyl groups at $\delta_{\mathrm{H}}(\mathrm{ppm})$ 1.00 (3H, Me-23), 0.87 (3H, Me-24), 0.99 (3H, Me-25), 1.75 (3H, Me-26), 1.72 (3H, Me-27), 0.76 (3H, Me-28), 1.12 (3H, Me-29), and 1.08 (3H, Me-30). Two olefinic protons (H-7 and H-15) were observed at $\delta_{\mathrm{H}}(\mathrm{ppm}) 5.45$ and 5.42 (each $1 \mathrm{H}, \mathrm{brs}$ ), together with two vinyl methyls proton resonating at $\delta_{\mathrm{H}}$ (ppm) $1.75(3 \mathrm{H}, \mathrm{s}, \mathrm{H}-26)$ and $\delta_{\mathrm{H}} 1.72(3 \mathrm{H}, \mathrm{s}, \mathrm{H}-27)$, indicating two trisubstituted double bonds of 1. One oxygenated methine signal was also observed at $\delta_{\mathrm{H}} 3.29 \mathrm{ppm}(1 \mathrm{H}, \mathrm{dd}, \mathrm{H}-3)$.

The structure of 1 was further defined by ${ }^{1} \mathrm{H}^{-1} \mathrm{H}$ COSY (correlated spectroscopy) and HMBC (heteronuclear multiple bond connectivity) spectra (Figure 2, Figures S5 and S6). The ${ }^{1} \mathrm{H}_{-}{ }^{1} \mathrm{H}$ COSY spectra showed couplings between $\mathrm{H}-1\left(\delta_{\mathrm{H}} 1.14\right) / \mathrm{H}-2\left(\delta_{\mathrm{H}} 1.65\right), \mathrm{H}-2\left(\delta_{\mathrm{H}} 1.65\right) / \mathrm{H}-3\left(\delta_{\mathrm{H}} 3.29\right), \mathrm{H}-9$ $\left(\delta_{\mathrm{H}} 1.66\right) / \mathrm{H}-11\left(\delta_{\mathrm{H}} 2.10\right), \mathrm{H}-11\left(\delta_{\mathrm{H}} 2.10\right) / \mathrm{H}-12\left(\delta_{\mathrm{H}} 1.98\right), \mathrm{H}-12\left(\delta_{\mathrm{H}} 1.98\right) / \mathrm{H}-13\left(\delta_{\mathrm{H}} 1.59\right)$, and H-19 $\left(\delta_{\mathrm{H}} 1.51\right) / \mathrm{H}-20\left(\delta_{\mathrm{H}} 2.77\right)$, supporting the presence of a onoceranoid-type triterpenoid structure. The oxygenated methine bearing a hydroxy group was located at C-3 by the HMBC correlations of $\mathrm{H}_{2}-1$ $\left(\delta_{\mathrm{H}} 1.86\right), \mathrm{H}_{3}-23\left(\delta_{\mathrm{H}} 1.00\right)$ and $\mathrm{H}_{3}-24\left(\delta_{\mathrm{H}} 0.87\right)$ to $\mathrm{C}-3\left(\delta_{\mathrm{C}} 79.1\right)$. The $\Delta^{7,8}$ and $\Delta^{14,15}$ double bonds were assigned by the HMBC correlations from $\mathrm{H}_{3}-26\left(\delta_{\mathrm{H}} 1.75\right)$ to $\mathrm{C}-7\left(\delta_{\mathrm{C}} 121.7\right), \mathrm{C}-8\left(\delta_{\mathrm{C}} 135.4\right), \mathrm{C}-9\left(\delta_{\mathrm{C}} 55.3\right)$; and $\mathrm{H}_{3}-27\left(\delta_{\mathrm{H}} 1.72\right)$ to $\mathrm{C}-13\left(\delta_{\mathrm{C}} 56.0\right), \mathrm{C}-14\left(\delta_{\mathrm{C}} 134.9\right), \mathrm{C}-15\left(\delta_{\mathrm{C}} 122.3\right)$. The ketone group was attached to $\mathrm{C}-21$ by the HMBC correlations of $\mathrm{H}_{2}-20\left(\delta_{\mathrm{H}} 2.77\right)$ and $\mathrm{H}_{3}-29\left(\delta_{\mathrm{H}} 1.12\right)$ to $\mathrm{C}-21\left(\delta_{\mathrm{C}} 217.0\right)$. This analysis indicated that compound 1 was similar to $3 \beta$-hydroxyonocera-8(26),14-dien-21-one [5], uniquely differing on the double bond position in the B ring. Based on the coupling constants of $\mathrm{H}-3$ ( $\mathrm{dd}, J=11.4$; $4.3 \mathrm{~Hz}$ ), the configuration of the hydroxyl group at C-3 was indicated in the $\beta$-equatorial position $[5,17]$. From the analyses, compound 1 was determined as 3-hydroxy-8,14-secogammacera-7,14-dien-21-one.

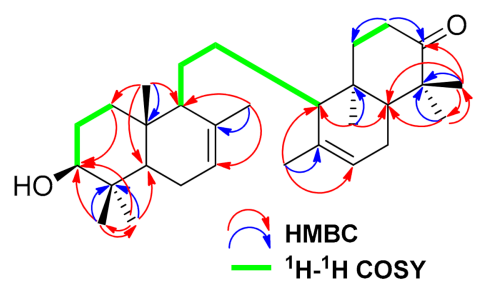

Figure 2. ${ }^{1} \mathrm{H}-{ }^{1} \mathrm{H}$ COSY and HMBC correlations of compound 1.

\section{Materials and Methods}

\subsection{General Experimental Procedures}

Mass spectrum was recorded on a waters Xevo QTOFMS (Waters, Milford, MA, USA). IR spectrum was measured on a One Perkin Elmer infrared-100 (Waltham, MA, USA) in KBr. NMR data were recorded on a Brucker spectrometer (Billerica, MA, USA) at $400 \mathrm{MHz}$ for ${ }^{1} \mathrm{H}$ and $120 \mathrm{MHz}$ for ${ }^{13} \mathrm{C}$ using TMS as an internal standard. Chromatographic separations were carried out on silica gel G60 (Merck, Darmstadt, Germany) and RP18 (Merck). TLC plates were precoated with silica gel GF254 (Merck, $0.25 \mathrm{~mm}$ ) and detection was achieved by spraying with $10 \%(v / v) \mathrm{H}_{2} \mathrm{SO}_{4}$ in ethanol, followed by heating. 


\subsection{Plant Material}

The fruit peels of L. domesticum Corr. cv kokossan (Meliaceae) was collected from Cililin, West Java, Indonesia in April 2018. The plant was identified and deposited in The Herbarium of Department of Biology, Faculty of Mathematics and Natural Sciences, Universitas Padjadjaran, Indonesia (Identification Number: 195/HB/08/2018).

\subsection{Cytotoxic Bioassay}

Cytotoxicity of the compound against MCF-7 human breast cancer cells was measured using MTT (Methyl Thiazoldiphenyl-Tetrazoliumbromide) assay. Stock culture was grown in flasks, containing Roswell Park Memorial Institute (RPMI) medium, respectively supplemented with 10\% $(v / v)$ feta bovine serum (FBS) and $1 \%(v / v)$ penicillin-streptomicin as an antibiotic. The culture was incubated at $37^{\circ} \mathrm{C}$ for $24 \mathrm{~h}$. The medium was changed, and tumor cells were detached and seeded in 96-well microliter plates. After, $24 \mathrm{~h}$, compounds were added to the wells. After $48 \mathrm{~h}$, cell viability was determined by measuring the metabolic conversion of yellow salt or 3-(4,5-dimethyltiazol-2-yl)-2,5-diphenyltetrazolium bromide to its insoluble formazan, which has a purple color product resulting from reduction in viable cells. Insoluble formazan was diluted with DMSO. The MTT assay results were read using spectrophotometer $\mathrm{UV}$ at $450 \mathrm{~nm}$. Compound 1 was evaluated at eight concentrations $(15.9 ; 34.0 ; 70.3 ; 140.7 ; 283.6 ; 567.3$; $1134.6 ; 2269.1 \mu \mathrm{M})$ in $100 \%$ DMSO with the final concentration of DMSO of $2.5 \%(v / v)$ in each well. Doxorubicin was used as a positive control. IC $_{50}$ values were calculated by the linear regression method using Microsoft Excel software.

\section{Conclusions}

A new onoceranoid triterpene, namely 3-hydroxy-8,14-secogammacera-7,14-dien-21-one (1), was isolated from fruit peels of L. domesticum Corr. cv kokossan (Meliaceae). This compound exhibited weak cytotoxic activity against MCF-7 human breast cancer cell lines with $\mathrm{IC}_{50}$ value of $717.5 \mu \mathrm{M}$.

Supplementary Materials: The following are available online, Figure S1. ${ }^{1} \mathrm{H}-\mathrm{NMR}$ spectrum of $\mathbf{1}$ (500 MHz in $\left.\mathrm{CDCl}_{3}\right)$, Figure S2. ${ }^{13} \mathrm{C}-\mathrm{NMR}$ spectrum of $\mathbf{1}\left(125 \mathrm{MHz}\right.$ in $\left.\mathrm{CDCl}_{3}\right)$, Figure S3. DEPT-135 _spectrum of $\mathbf{1}(125 \mathrm{MHz}$ in $\mathrm{CDCl}_{3}$ ), Figure S4. HSQC Spectrum of $\mathbf{1}$, Figure $55 .{ }^{1} \mathrm{H}^{-1} \mathrm{H}$ COSY spectrum of $\mathbf{1}$, Figure S6. HMBC spectrum of $\mathbf{1}$, Figure S7. Infrared Spectrum of $\mathbf{1}$ (in KBr), Figure S8. HR-TOF-MS Spectrum of 1, Figure S9. TLC Profile of $\mathbf{1 .}$

Author Contributions: Conceptualization, T.M. and U.S.; methodology, N.K.P. and Z;; software validation, S.F.; formal analysis, S.F.; investigation, R.M. and J.A.A.; resources, T.M. and M.Y.; data curation, N.K.P. and Z.; writing —original draft preparation, Z.; writing—review and editing, J.A.A. and M.Y.; visualization, R.M.; supervision, T.M., M.Y., and U.S.; project administration, N.K.P.; funding acquisition T.M. All authors have read and agreed to the published version of the manuscript.

Funding: This research was funded by PTM, Ministry of Research, Technology and Higher Education, Indonesia, grant number: 1827/UN6.3.1/LT/2020 (T.M.).

Acknowledgments: We thank to Joko Kusmoro, M.P. at Jatinangor Herbarium for identification of the plant material, Ahmad Darmawan at the Research Center for Chemistry, Indonesian Science Institute, for performing the NMR measurements, Kansi at the Center Laboratory of Universitas Padjadjaran for performing the HR-TOF-MS measurements, Tenny Putri Wikayani and Nurul Qomarilla at Cells and Tissues Culture Laboratory, Faculty of Medicine, Universitas Padjadjaran for the cytotoxic assay.

Conflicts of Interest: The authors declare no conflict of interest.

\section{References}

1. Techavuthiporn, C. Langsat-Lansium Domesticum. Exotic Fruits Reference Guides; Rodrigues, S., de Brito, E.S., Silva, E.d.O., Eds.; Academic Press: London, UK, 2018; pp. 279-283.

2. Mayanti, T.; Tjokronegoro, R.; Supratman, U.; Mukhtar, M.R.; Awang, K.; Hadi, A.H.A. Antifeedant triterpenoids from the seeds and bark of Lansium domesticum cv kokossan (Meliaceae). Molecules 2011, 16, 2785-2795. [CrossRef]

3. Dong, S.H.; Zhang, C.R.; Dong, L.; Wu, Y.; Yue, J.M. Onoceranoid-type triterpenoids from Lansium domesticum. J. Nat. Prod. 2011, 74, 1042-1048. [CrossRef] [PubMed] 
4. Nishizawa, M.; Nishide, H.; Hayashi, Y.; Kosela, S. The structure of lansioside A: A novel triterpene glycoside with amino-sugar from Lansium domesticum. Tetrahedron Lett. 1982, 23, 1349-1350. [CrossRef]

5. Nishizawa, M.; Nishide, H.; Kosela, S.; Hayashi, Y. Structure of lansiosides: Biologically active new triterpene glycosides from Lansium domesticum. J. Org. Chem. 1983, 48, 4462-4466. [CrossRef]

6. Tanaka, T.; Ishibashi, M.; Fujimoto, H.; Okuyama, E.; Koyano, T.; Kowiyhayakorn, T.; Hayashi, M.; Komiyama, K. New onoceranoid constituents from Lansium domesticum. J. Nat. Prod. 2002, 65, 1709-1711. [CrossRef] [PubMed]

7. Habaguchi, K.; Watanabe, M.; Nakadaira, Y.; Nakanishi, K.; Kaing, A.K.; Lim, F.L. The full structures of lansic acid and its minor congener, an unsymmetric onoceradienedione. Tetrahedron Lett. 1986, 34, 3731-3734. [CrossRef]

8. Mayanti, T.; Supratman, U.; Mukhtar, M.R.; Awang, K.; Ng, S.W. Kokosanolide from the seed of Lansium domesticum Corr. Acta Crystallogr. 2009, E65, o750.

9. Supratman, U.; Mayanti, T.; Awang, K.; Mukhtar, M.R.; Ng, S.W. 14-Hydroxy-8,14-secogammacera-7-ene-3,21-dione from the bark of Lansium domesticum Corr. Acta Crystallogr. 2010, E66, o1621.

10. Manosroi, A.; Jantrawut, P.; Sainakham, M.; Manosroi, W.; Manosroi, J. Anticaner activities of the extract from longkong (Lansium domesticum) young fruits. Pharm. Biol. 2012, 50, 1397-1407. [CrossRef] [PubMed]

11. Ragasa, C.Y.; Labrador, P.; Rideout, J.A. Antimicrobial terpenoid from Lansium domesticum. Philipp. Agric. Sci. 2006, 89, 101-105.

12. Leatemia, J.A.; Isman, M.B. Insecticidal activity of crude seed extracts of Annona. spp., Lansium domesticum and Sandoricum koetjape against lepidopteran larvae. Phytopatasitica 2004, 32, 30-37. [CrossRef]

13. Saewan, N.; Sutherland, J.D.; Chantrapromma, K. Antimalarial tetranortriterpenoids from the seed of Lansium domesticum Corr. Phytrochemistry 2006, 67, 2288-2293. [CrossRef] [PubMed]

14. Matsumoto, T.; Kitagawa, T.; Teo, S.; Anai, Y.; Ikeda, R.; Imahori, D.; Ahmad, H.S.; Watanabe, T. Structures and antimutagenic effects of onoceranoid-type triterpenoids from the leaves of Lansium domesticum. J. Nat. Prod. 2018, 81, 2187-2194. [CrossRef] [PubMed]

15. Matsumoto, T.; Kitagawa, T.; Ohta, T.; Yoshida, T.; Imahori, D.; Teo, S.; Ahmad, H.S.; Watanabe, T. Structures of triterpenoids from the leaves of Lansium domesticum. J. Nat. Med. 2019, 73, 727-734. [CrossRef] [PubMed]

16. Mayanti, T.; Sianturi, J.; Harneti, D.; Darwati; Supratman, U.; Rosli, M.M.; Fun, H.K. 9,19-Cyclolanost-24-en-3-one,21,23-epoxy-21,22-dihydroxy $(21 R, 22 S, 23 S)$ from the leaves of Lansium domesticum Corr cv kokossan. Molbank 2015, 2015, M880. [CrossRef]

17. Hou, Y.; Cao, S.; Brodie, P.J.; Miller, J.S.; Birkinshaw, C.; Andrianjafy, M.N.; Andriantsiferana, R.; Rasamison, V.E.; Tendyke, K.; Shen, Y.; et al. Euphane triterpenoids of Cassipourea lanceolata from the Madagascar rainforest. Phytochemistry 2010, 71, 669-674. [CrossRef] [PubMed]

Sample Availability: Samples of the compounds $\mathbf{1}$ are available from the authors.

(C) 2020 by the authors. Licensee MDPI, Basel, Switzerland. This article is an open access article distributed under the terms and conditions of the Creative Commons Attribution (CC BY) license (http://creativecommons.org/licenses/by/4.0/). 